\title{
Infection of Commercial Hybrid Primula Seed by Botrytis cinerea and Latent Disease Spread Through the Plants
}

\author{
S. E. Barnes and M. W. Shaw
}

School of Plant Sciences, The University of Reading, Whiteknights, Reading, RG6 6AU, UK.

Current address of S. E. Barnes: School of Life and Environmental Sciences, University of Nottingham, University Park, Nottingham, NG7 2RD, UK.

Accepted for publication 10 December 2002.

\begin{abstract}
Barnes, S. E., and Shaw, M. W. 2003. Infection of commercial hybrid primula seed by Botrytis cinerea and latent disease spread through the plants. Phytopathology 93:573-578.

Botrytis cinerea occurred commonly on cultivated Primula $\times$ polyantha seed. The fungus was mostly on the outside of the seed but sometimes

Young, commercially produced $P$. xpolyantha plants frequently had symptomless $B$. cinerea infections spread throughout the plants for up to 3 months, with symptoms appearing only at flowering. Single genetic individuals of $B$. cinerea, as determined by DNA fingerprinting, often were dispersed widely throughout an apparently healthy plant. Plants could, however, contain more than one isolate.
\end{abstract} was present within the seed. The fungus frequently caused disease at maturity in plants grown from the seed, demonstrated by growing plants in a filtered airflow, isolated from other possible sources of infection.
Additional keywords: endophyte, gray mold, primrose, seed health, systemic.
Botrytis cinerea causes an economically important disease of container-grown ornamentals such as primula and cyclamen. This disease either reduces marketability of the plants or renders them unmarketable. The inoculum for the disease generally is thought to be spread by wind or splash dispersal of conidia onto aboveground plant parts. However, seedborne disease also may be important.

Seedborne B. cinerea is associated with a number of plant species, including Stylosanthes spp., a forage crop in sub-Saharan Africa (20), chickpea (6), flax and lettuce $(13,14)$, lentil (18), and linseed (19). In linseed, $100 \%$ of the outer integument was found to be infected after 14 days of incubation (10). In total, Botrytis spp. have been isolated from seed of more than 50 flower, forage and vegetable species.

However, seedborne pathogens are relevant only if they can be transmitted to the plant growing from the seed (15). This is seen with infection of clover seed by $B$. anthophila, where the mycelium infects the seed and exists as a systemic pathogen (12). $B$. cinerea has been found to be transmitted from the infected seed to emerging seedlings in linseed and, after the seedling stage, few disease symptoms are seen until the right physiological stage of the crop is reached (9). B. fabae has been isolated from most parts of field bean seedlings grown from infected seed, although no obvious symptoms were present. The number of plants which later showed signs of sporulating pathogen was found to be temperature dependent (11). Some seedborne fungi such as Alternaria spp. are found to be associated with the plant throughout its growing season (14), and symptoms only appear once the environmental conditions are right or the host undergoes some physiological change.

Latent period has been defined as the period from infection until spore production (21). Latent infection by $B$. cinerea has been noted especially in grape (7), where prior infections of flowers

Corresponding author: M.W Shaw; E-mail address: m.w.shaw@reading.ac.uk

Publication no. P-2003-0224-02R

(c) 2003 The American Phytopathological Society cause bunch rot later on in the season. Latency also has been found in raspberry (5), where disease of the fruit can result from germination of conidia on the stigma, with hyphae growing through the style. The same mechanism occurs in strawberry (5). Latent infection in parts of the plant other than the flower also has been observed in strawberry (4), where $B$. cinerea readily infects young leaves that then remain asymptomatic for up to 8 months until they senesce. In hybrid primula, we observed that inoculations with chlorate-resistant mutants produced no symptoms until flowering, regardless of when the inoculation was made (2).

The experiments reported here were undertaken with three aims: first, to determine if $B$. cinerea could be found in primula seed; second, to determine the prevalence of latent $B$. cinerea in healthy-looking hybrid primula plants; and third, to establish the relation between seedborne infection and epidemics in mature crops. An important intermediate goal was to determine whether latent infections of multiple plant parts were independent of each other or represented internal growth of one isolate.

\section{MATERIALS AND METHODS}

Surface sterilization method. To sterilize seed, they were soaked in a $20 \%$ solution of Domestos $(0.1 \%$ hypochlorite) for $5 \mathrm{~min}$. The effectiveness of this was tested on seed inoculated in two ways. In the first method, seed were mixed with dry conidia in a glass vial, then left for $1 \mathrm{~h}$ at room temperature; in the second method, seed were left to soak overnight in a suspension of $10^{6}$ conidia per $\mathrm{ml}$ and dried in a flow of sterile air for $2 \mathrm{~h}$. The seed were surface sterilized and plated onto $3 \%$ malt extract agar (MEA). In both cases, a chlorate-resistant mutant was used as a marked isolate in order to distinguish the isolate inoculated from any pre-existing infection.

The chlorate-resistant mutants were generated by inoculating $B$. cinerea isolates onto minimal medium, which contained ammonium nitrate at $0.1 \mathrm{~g} \mathrm{liter}^{-1}$, sucrose at $15 \mathrm{~g} \mathrm{liter}^{-1}$, and agar at $15 \mathrm{~g} \mathrm{liter}^{-1}$, and incubating for 3 days at $18^{\circ} \mathrm{C}$. Growing cultures were inoculated onto the minimal medium amended with potassium chlorate $\left(\mathrm{KClO}_{3}\right)$ at $30 \mathrm{~g} \mathrm{liter}^{-1}$ and incubated at $18^{\circ} \mathrm{C}$ for up to 4 weeks, 
during which the cultures were monitored for rapidly growing sectors. These sectors were transferred to fresh plates of chlorateamended minimal media for 2 weeks at $18^{\circ} \mathrm{C}$ and from these to $3 \%$ MEA to allow growth and sporulation. Only isolates BC G (isolated from primula plants at a commercial grower in February 2000) and BC 133 (an isolate from primula plants grown at Reading University) showed the appropriate sectors. To ensure that the cultures were pathogenic, conidia were inoculated onto entire plants; sporulating pathogen was re-isolated and cultured on chlorate-amended minimal media plates to ensure that the dense growth still occurred.

Incidence of seed infected by $\boldsymbol{B}$. cinerea. Batches of seed were obtained from commercial growers. In most cases, half the batch was surface sterilized in a $20 \%$ solution of Domestos for $5 \mathrm{~min}$. The seed then were left to dry in a laminar flow cabinet. All seed then were placed on $3 \%$ MEA and incubated at $18^{\circ} \mathrm{C}$ in the dark for 6 to 8 days. Isolations were made from all seeds showing fungal growth.

A range of varieties of seed from four commercial producers and three retailers were examined. The seed had been stored for various lengths of time before tests; their true age was unknown.

Transmission of seedborne pathogen to growing plants. In order to determine if $B$. cinerea present in the seed would cause disease in mature plants, an isolation plant propagator was used (Burkhard Manufacturing Co. Ltd., Rickmansworth, Hertfordshire, UK). This is an apparatus designed to grow plants in an air stream free of fungal spores. Plants are grown in separate isolated pots located on trays, which have a reservoir of water in the bottom. Wicks, which run into each pot through the air pipe running up the center, are the only contact with the water. Filtered air is pumped through plastic piping into each tray. The air supply is shared between all the pots. The pots are covered with a transparent plastic dome, which contains two holes to allow the air to escape. The positive pressure of this air prevents contamination.

To determine if conidia were entering through the filter, three plates containing Botrytis spp.-selective medium (9) were placed in the pots for $8 \mathrm{~h}$, or inverted over the exit air holes of the propagator, while open sporulating plates of $B$. cinerea were agitated for $15 \mathrm{~min}$ in front of the air intake.

In both experiments done in the isolation plant propagator, primula seed were sown in the pots and left to grow. The seed came from a batch of which $20 \%$ had been shown in the agar plate experiments to be infected after surface sterilization. In order to determine if $B$. cinerea in the soil contributed toward any final disease, 60 of the pots contained sterilized soil and 60 contained noninoculated, unsterilized soil. The soil was sterilized by autoclaving. In order to confirm that the conditions within the propagator were suitable for infection, 10 of the plants grown from seed were inoculated with a puff of conidia at the base of the plants, while the plants were at the two- to three-leaf stage. This inoculation was done by putting the tip of a Pasteur pipette with the bulb squeezed in a cryovial of spores, releasing the bulb to suck spores into the pipette, and then inoculating the plants with $B$. cinerea by sharply squeezing the bulb of the pipette close to the base of the plant. Ten more plants were inoculated 1 month later.

TABLE 1. Isolations of Botrytis cinerea from primula seed inoculated with dry conidia or a spore suspension after surface sterilization

\begin{tabular}{lcc}
\hline & \multicolumn{2}{c}{ Seed contaminated $(\%)^{\mathrm{z}}$} \\
\cline { 2 - 3 } Treatment $^{\mathrm{y}}$ & $\begin{array}{c}\text { Before } \\
\text { sterilization }\end{array}$ & $\begin{array}{c}\text { After } \\
\text { sterilization }\end{array}$ \\
\hline Seeds dusted with dry conidia & $92 \mathrm{a}$ & $0 \mathrm{~b}$ \\
Seeds soaked overnight in a spore suspension & $72 \mathrm{a}$ & $0 \mathrm{~b}$ \\
Control (noninoculated seeds) & $40 \mathrm{a}$ & $4 \mathrm{~b}$ \\
\hline
\end{tabular}

y Twenty-five seed were used for each test.

${ }^{\mathrm{z}}$ Numbers in the same row followed by a different letter are significantly different at $P=0.01$.
The plants were removed from the plant propagator to be inoculated in the laboratory, then returned to the isolation plant propagator.

Changes in the experimental protocol became necessary in both experiments. First, some seed did not germinate, because the wicks did not work. These pots were equally from the sterilized and nonsterilized soil treatments. The dry pots were refilled with soil and new wicks put in place. Pregrown young plants, from a commercial grower, were planted in the pots. In the second experiment, the plant propagator had to be turned off for a period of 3 days because of greenhouse cleaning. By this stage, the top two trays had already been removed and only the bottom two trays remained, because the top plants flowered faster than the bottom plants. While the power was off, the entire propagator was sealed in plastic to prevent contamination.

At the end of the experiment, the plants were removed from the propagator and the presence of sporulating $B$. cinerea was recorded. The second leaf from the bottom was removed from each plant, surface sterilized, and plated on 3\% MEA to check for $B$. cinerea infections not causing symptoms.

Position of latent disease within the plant. Fifty-five primula plants were received from a grower at the two- to four-leaf stage. To determine the level of latent infection, the leaves from five plants were harvested, surface sterilized, for $10 \mathrm{~min}$ in $20 \%$ Domestos, plated onto $3 \% \mathrm{MEA}$, and incubated at $18^{\circ} \mathrm{C}$. This was repeated weekly for 11 weeks, until the plants were mature. The location of infection was determined in a further 48 mature primula plants which had been grown from seed in the glasshouse at Reading University under a normal light and temperature regime. These plants had necrosis on their lower leaves but were otherwise healthy. Forty-four of the plants were surface sterilized for $10 \mathrm{~min}$ in $20 \%$ Domestos. All plants were then aseptically dissected into top leaf tips; petiole of top leaves; bottom leaf tips; petiole of bottom leaves; old flowers; young flowers, and roots. Two leaf tips and two leaf bases were tested from each of the top and bottom leaves and one to two flowers were tested per plant. Approximately 5 to $10 \%$ of the total root system was tested per plant, depending on the overall root size. These pieces were plated onto 3\% MEA and examined at intervals for sporulating colonies of $B$. cinerea.

DNA extractions. Isolates were grown on 3\% MEA. A disk $5 \mathrm{~mm}$ in diameter was taken from the edge of the sporulating culture and added to $50 \mathrm{ml}$ of $3 \%$ malt extract broth in a 100-ml conical flask. Flasks were incubated on a rotary shaker in a constant temperature growth chamber (Conviron, Canada) for 5 days at $18^{\circ} \mathrm{C}$ with $12 \mathrm{~h}$ of light and $12 \mathrm{~h}$ of dark.

The flasks were removed and the culture filtered through two layers of sterilized muslin to retain the mycelium, which was washed twice with sterilized nanopure water. The mycelium was placed in a sterilized mortar and frozen in liquid nitrogen for $5 \mathrm{~min}$. The mycelium was ground to a fine powder under liquid nitrogen with a sterilized mortar and pestle and placed in an Eppendorf tube. Eppendorf tubes were frozen at $-20^{\circ} \mathrm{C}$ until the DNA was extracted, using a Qiagen DNeasy (Crawley, W. Sussex, UK) plant minikit according to the manufacturer's instructions.

DNA quantification. The extracted DNA, plus $1 \mu \mathrm{l}$ of loading buffer, was run on a $1 \%$ agarose gel containing agarose in Trisacetate-EDTA buffer with ethidium bromide. DNA concentrations were assessed visually under UV light and adjusted to approximately equal intensity by choosing an appropriate dilution.

Intersimple sequence repeat fingerprinting. Each reaction mix contained $2 \mu \mathrm{l}$ of fungal DNA, $2 \mu \mathrm{l}$ of $\mathrm{NH}_{4}, 0.6 \mu \mathrm{l}$ of $\mathrm{MgCl}_{2}$, $0.4 \mu \mathrm{l}$ of dNTPs (from a stock solution prepared as $50 \mu \mathrm{l}$ of each $\mathrm{dNTP}$ and $200 \mu \mathrm{l}$ of sterile nanopure water), $0.3 \mu \mathrm{l}$ of primer mix $888\left(5^{\prime} \mathrm{BDB}[\mathrm{CA}]_{7} 3^{\prime}\right.$, where $\mathrm{B}$ is $\mathrm{C}, \mathrm{G}$, and $\mathrm{T}$ in equal frequency and $\mathrm{D}$ is $\mathrm{G}, \mathrm{T}$, and $\mathrm{A}$ in equal frequency; Genset Oligos, Genset Corp. Singapore), $0.1 \mu \mathrm{l}$ of Taq DNA polymerase, and $14.6 \mu \mathrm{l}$ of sterile nanopure water in a $50-\mu l$ Eppendorf tube. Two template 
concentrations were used for each sample, differing by a factor of 10. Amplifications were done in a GeneAmp PCR system 9700 (Applied Biosystems, Warington, UK) thermocycler. Initial denaturing was at $95^{\circ} \mathrm{C}$ for $3 \mathrm{~min}$, followed by 30 cycles of denaturing at $94^{\circ} \mathrm{C}$ for $1 \mathrm{~min}$, annealing at $55^{\circ} \mathrm{C}$ for $2 \mathrm{~min}$, and extension at $72^{\circ} \mathrm{C}$ for $30 \mathrm{~s}$. A final extension step was done at $72^{\circ} \mathrm{C}$ for $5 \mathrm{~min}$, followed by storage at $4^{\circ} \mathrm{C}$.

DNA band visualization. Precast acrylamide gels (Cleangel $48 \mathrm{~s}$, Pharmacia Biotech) were rehydrated, gel side down, in rehydration buffer (112 mM Tris acetate, $\mathrm{pH}$ 6.4) for $1 \mathrm{~h}$. The gel was placed onto a premoistened flat bed gel runner, which had been cooled to $10^{\circ} \mathrm{C}$. Two wicks, composed of five strips of filter paper cut into 4-by-25-cm strips, were soaked in $20 \mathrm{ml}$ of electrode buffer $(0.2 \mathrm{M}$ Tris base, $0.2 \mathrm{M}$ tricine, $0.55 \%$ [wt/vol] sodium dodecyl sulfate, $\mathrm{pH}$ 8.0) each and placed so that they overlaid the gel by $0.5 \mathrm{~cm}$ on either end.

Polymerase chain reaction (PCR) product $(5 \mu \mathrm{l})$ was mixed with $2 \mu \mathrm{l}$ of loading buffer (20\% sucrose, $10 \%$ Ficoll, $0.05 \%$ bromophenol blue, $0.05 \%$ xylene cyanol, $1 \mathrm{mM}$ EDTA, and $5 \mathrm{M}$ urea) and loaded into the gel. Anode and cathode then were positioned $0.5 \mathrm{~cm}$ from the opposite side of each wick. The electrophoresis used a three-stage program: $20 \mathrm{~min}$ at $200 \mathrm{~m}$ Amax, $10 \mathrm{~W}$ max; $50 \mathrm{~min}$ at $380 \mathrm{~m}$ Amax, $20 \mathrm{~W} \max$; and $60 \mathrm{~min}$ at $450 \mathrm{~m}$ Amax, $20 \mathrm{~W}$ max.

Bands were detected by silver staining. Gels were fixed for $60 \mathrm{~min}$ in $250 \mathrm{ml}$ of $10 \%$ acetic acid and then given four 2-min washes in nanopure water. They were silver stained for $30 \mathrm{~min}$ in $200 \mathrm{ml}$ of freshly prepared $0.1 \%$ (wt/vol) silver nitrate with $200 \mu \mathrm{l}$ of $40 \%$ (wt/vol) formaldehyde added immediately prior to use. Gels then were rinsed for $20 \mathrm{~s}$ in nanopure water and developed at $10^{\circ} \mathrm{C}$ in $200 \mathrm{ml}$ of $2.5 \%$ sodium carbonate with $200 \mu \mathrm{l}$ of $2 \%$ (wt/vol) sodium thiosulphate and $250 \mu \mathrm{l}$ of formaldehyde added immediately prior to use. Development continued until the bands were clearly visible (approximately $5 \mathrm{~min}$ ) and was stopped with $200 \mathrm{ml}$ of $2 \%$ (wt/vol) glycine and $0.5 \%$ (wt/vol) EDTA- $\mathrm{Na}_{2}$ for $10 \mathrm{~min}$. The gel was impregnated in $250 \mathrm{ml}$ of $5 \%$ ( $\mathrm{vol} / \mathrm{vol}$ ) glycerol for $10 \mathrm{~min}$ in order to preserve it and air dried overnight.

Band patterns were compared by photocopying the gels onto transparency sheets, cutting out the separate pairs of lanes corresponding to different template concentrations, and overlaying them one at a time onto the original. Any differences in presence or position of the bands were noted. PCR, intersimple sequence repeat (iSSR) fingerprinting, and assignments to groups were repeated twice.

Statistical analysis. Counts were analyzed in Genstat (VSN International, Oxford UK) using generalized linear models with a logit link function. The association between isolate band patterns and plants was tested using a measure of association. If the frequency of band pattern $i$ in the data was $p_{i}, r_{j}$ isolations were made from plant $j$, and $k_{i j}$ isolates of type $i$ were found in plant $j$, then the association was defined as

$$
I=\sum_{i, j} \frac{k_{i j}}{r_{j}} \log \left(p_{i}\right)
$$

Random assignments of the observed numbers of different types of isolates to the plants were made and the measure $I$ calculated. Percentage points of the distribution of $I$ were calculated from 100,000 simulated random assignments of band patterns to plants, keeping the total number of individuals with each pattern and the number of isolations from each plant constant.

\section{RESULTS}

Surface sterilization method. Surface sterilization removed $B$. cinerea from the seed coats of Primula xpolyantha seed inoculated by either technique (Table 1). A single seed, not inoculated, gave rise to a colony after sterilization.

Incidence of seed infection by $\boldsymbol{B}$. cinerea. B. cinerea occurred externally on the $P$. xpolyantha seed obtained from most growers (Table 2). Seed from one grower also had a high incidence of $B$. cinerea that was not removed by surface sterilization.

Transmission of seedborne pathogen to growing $\boldsymbol{P}$. xpolyantha. $B$. cinerea was isolated from mature leaves of primula, grown from noninoculated seed within the isolation plant propagator. Approximately half of the plants were infected although only 10 showed sporulation. The background level of seedborne $B$. cinerea was not known in this case. In plants initially grown outside the incubator and placed in the pots as plugs 4 months later, the proportion of leaves from which isolations could be made was significantly less $\left(\chi^{2}=6.3, P=0.01\right)$, with only $41 \%$ infected (Table 3). For plants grown from seed, there were no significant differences in infection incidence between inoculated and un-

TABLE 3. Number of mature primula plants found to harbor Botrytis cinerea when grown from seed in an isolation plant propagator or transferred there as plugs, in relation to soil treatment and seed inoculation

\begin{tabular}{lllcc}
\hline Plants from & \multicolumn{1}{c}{ Soil } & \multicolumn{1}{c}{ Seed } & $\begin{array}{c}\text { Total } \\
\text { sample }\end{array}$ & $\begin{array}{c}\text { Detection } \\
(\%)^{\mathrm{z}}\end{array}$ \\
\hline Seed & Sterilized & Inoculated & 11 & $73 \mathrm{a}$ \\
& Not sterilized & Not inoculated & 66 & $59 \mathrm{a}$ \\
& Inoculated & 25 & $60 \mathrm{a}$ \\
& Not sterilized & Not inoculated & 64 & $70 \mathrm{a}$ \\
Plugs & Not inoculated & 59 & $41 \mathrm{~b}$ \\
\hline
\end{tabular}

y Both repeat experiments combined.

z Numbers followed by the same letter do not differ significantly at $P=0.05$, using a generalized linear model with a binomial error distribution and logit link function.

TABLE 2. Percentage of primula seed and seed batches from which Botrytis cinerea was isolated before and after surface sterilization in seed from various suppliers

\begin{tabular}{|c|c|c|c|c|c|c|}
\hline \multirow[b]{3}{*}{ Weeks from receipt } & \multirow[b]{3}{*}{ Seed producer } & \multirow[b]{3}{*}{ No. cultivars tested } & \multicolumn{4}{|c|}{ Seed } \\
\hline & & & \multicolumn{2}{|c|}{ Nonsterilized } & \multicolumn{2}{|c|}{ Surface sterilized } \\
\hline & & & No. cultivars infected & Seed infected $(\%)^{\mathrm{w}}$ & No. cultivars infected & Seed infected (\%) \\
\hline$>24$ & Wholesale & 17 & 7 & $31 \pm 15^{x}$ & 0 & 0 \\
\hline$>24$ & Wholesale & 3 & 3 & $33 \pm 17^{x}$ & 0 & 0 \\
\hline$>24$ & Wholesale & 3 & 1 & $17 \pm 6^{y}$ & 0 & 0 \\
\hline$>24$ & Wholesale & 4 & 1 & $17 \pm 6^{y}$ & 1 & $16 \pm 6^{y}$ \\
\hline 1 & Wholesale & $5^{z}$ & 1 & $30 \pm 5^{y}$ & 4 & $20 \pm 0^{x y}$ \\
\hline 1 & Retailer & 3 & 3 & $24 \pm 25^{x}$ & 0 & 0 \\
\hline 1 & Retailer & 2 & 1 & $8 \pm 1^{y}$ & 0 & 0 \\
\hline 1 & Retailer & 2 & 2 & $22 \pm 3^{x}$ & 0 & 0 \\
\hline
\end{tabular}

${ }^{\mathrm{w}}$ Mean proportion infected in batches with any $B$. cinerea detected.

$x$ Based on variation between cultivars.

y Based on a binomial confidence limit for a sample size of 20 .

$\mathrm{z}$ Three of the samples plated out only after surface sterilization. 
TABLE 4. Percentage of apparently healthy surface-sterilized parts of primula plants from which Botrytis cinerea could be isolated ${ }^{\mathrm{w}}$

\begin{tabular}{lcccccc}
\hline & \multicolumn{5}{c}{ Age in weeks } & \\
\cline { 2 - 5 } & 4 & $5-7$ & $9-11$ & $12-14$ & 15 & Mean $^{\mathrm{x}}$ \\
\hline Plants sampled & 14 & 15 & 15 & 15 & 20 & $\ldots$ \\
Plants infected $(\%)^{\mathrm{y}}$ & $43 \mathrm{a}$ & $93 \mathrm{~b}$ & $100 \mathrm{~b}$ & $73 \mathrm{c}$ & $100 \mathrm{~b}$ & $\ldots$ \\
Parts infected $(\%)^{\mathrm{z}}$ & 100 & 67 & 73 & 70 & 81 & $\ldots$ \\
Roots & 43 & 43 & 87 & 33 & 80 & $56 \mathrm{a}$ \\
Flowers & $\mathrm{NP}$ & $\mathrm{NP}$ & $\mathrm{NP}$ & 33 & 45 & $38 \mathrm{a}$ \\
Top leaf tip & 43 & 53 & 67 & 40 & 70 & $54 \mathrm{a}$ \\
Top leaf base & 43 & 53 & 67 & 53 & 75 & $58 \mathrm{a}$ \\
Bottom leaf tip & 43 & 80 & 73 & 40 & 75 & $63 \mathrm{a}$ \\
Bottom leaf base & 43 & 80 & 73 & 53 & 60 & $65 \mathrm{a}$ \\
\hline
\end{tabular}

${ }^{\mathrm{w}}$ No data were obtained in week 8 ; $\mathrm{NP}=$ organ not yet present in plants.

x Numbers followed by the same letter are not significantly different at $P=$ 0.05 using a generalized linear model of the counts, with binomial error distribution and a logit link function.

y Percentage of plants tested in which at least one part was infected; numbers followed by different letters differ from the remainder at $P=0.05$ according to $\chi^{2}$ using a generalized linear model of the counts.

${ }^{z}$ Percentage of parts infected in plants with at least one part infected.

TABLE 5. Percentage of apparently healthy parts of primula plants grown from seed in an open greenhouse from which Botrytis cinerea could be isolated $^{\mathrm{x}}$

\begin{tabular}{lcc}
\hline Plant part & Surface sterilized $^{\mathrm{y}}$ & Nonsterilized $^{\mathrm{z}}$ \\
\hline Roots & $71 \mathrm{a}$ & 50 \\
Flowers & $85 \mathrm{a}$ & 50 \\
Top leaf tip & $73 \mathrm{a}$ & 100 \\
Top leaf base & $58 \mathrm{a}$ & 100 \\
Bottom leaf tip & $79 \mathrm{a}$ & 75 \\
Bottom leaf base & $79 \mathrm{a}$ & 75 \\
\hline
\end{tabular}

${ }^{x}$ Forty-eight mature plants were tested, four without surface sterilization.

y Numbers followed by the same letter are not significantly different at $P=$ 0.05 according to $\chi^{2}$.

${ }^{z}$ Sample size of four too small for meaningful statistical analysis between parts.

inoculated seed, or between sterilized and nonsterilized soil, or between repeat experiments.

Position of latent $B$. cinerea within $P$. xpolyantha plants. Plants 4 weeks of age and older showed a similar level of infection in all parts. There were fewer infected plants in the first batch tested $(P<0.001$, using a generalized linear model $)$, but there was no systematic trend over time (Table 4 ). The first batch of plants also showed a very strong association between one plant part and another: if a plant was infected anywhere, it was infected everywhere. This association was slightly less strong subsequently. Once the flowers began to develop, B. cinerea was found within them.

In mature plants, there were no significant differences in the proportions of different plant parts infected $\left(\chi^{2}=1.91,5 \mathrm{df}, P>\right.$ 0.90) (Table 5). All plants had some level of infection: $27 \%$ of the plants had all parts infected, $25 \%$ had $5 / 6$ parts infected, $23 \%$ had $4 / 6$ parts infected, $19 \%$ had 3/6 parts infected, and $6 \%$ had 2/6 parts infected. These proportions do not differ from the combinations expected by chance, given the average proportion infected, and testing the differences by $\chi^{2}$.

DNA band visualization. $P$. $\times$ polyantha plants grown to flowering in an open glasshouse were dissected, isolations made from the various parts, and iSSR banding patterns visualized for as many isolates as possible (Fig. 1). In 9 of 10 cases, two or more isolations from distinct parts of a single plant yielded the same $B$. cinerea banding pattern (Table 6). Most plants harbored isolates with several distinct band patterns, and several band patterns occurred in isolates from more than one plant. However, multiple recoveries of individual isolate patterns from single plants were much commoner than expected by chance. Overall, the pattern was significantly different from a random assignment of isolates

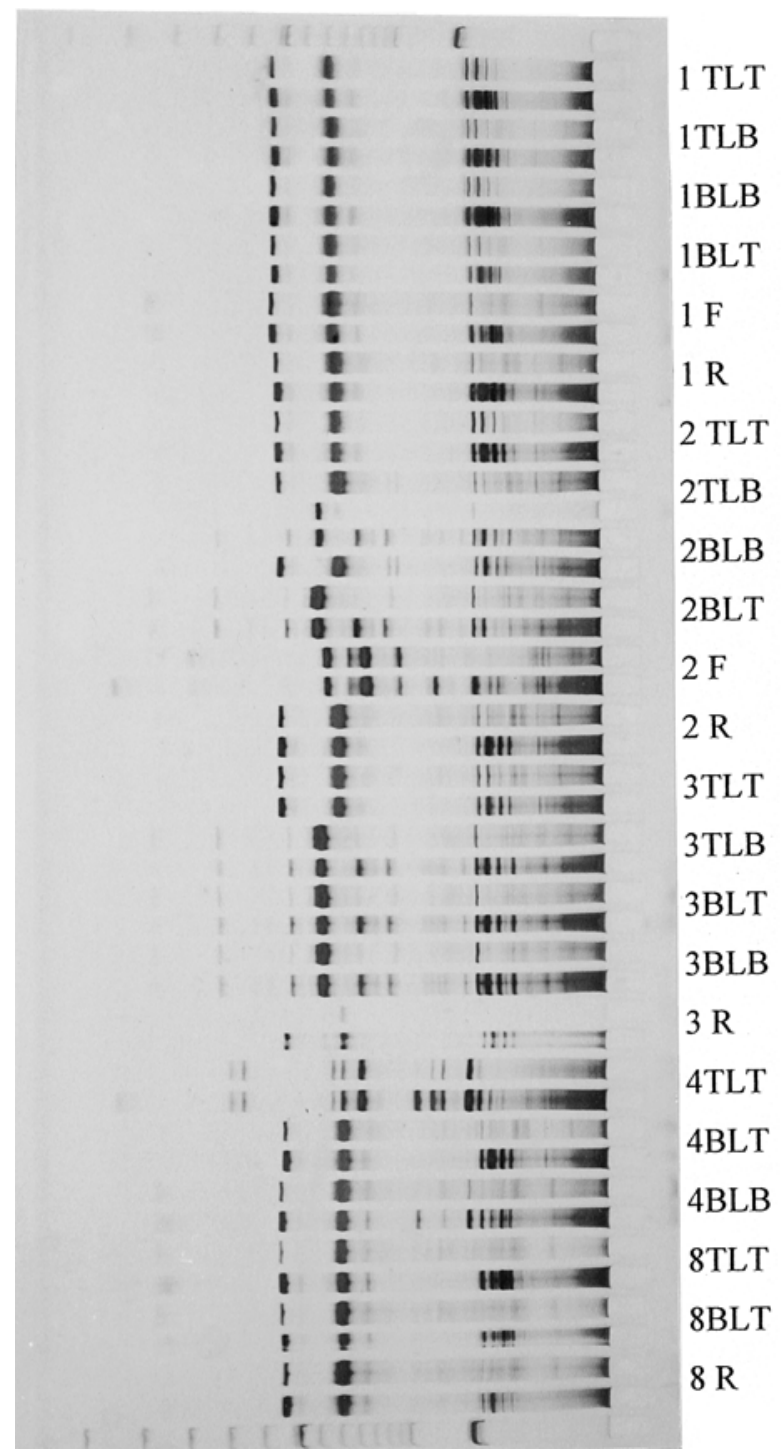

Fig. 1. Intersimple-sequence repeat DNA band patterns of 23 isolates of Botrytis cinerea from different parts of five flowering but symptomless plants from a crop grown in an open glasshouse at Reading from commercial plug plants. Each isolate is represented in a pair of adjacent lanes, with polymerase chain reaction done from the same extract at standard and 1/10 dilutions. Numbers distinguish the plants from which isolates came. Letters represent plant parts: F, flower; TLT, top leaf tip; TLB, top leaf base; BLT, bottom leaf tip; BLB, bottom leaf base; R, root.

to plants ( $P \leq 0.0001$, using the randomization test described). In plants 1 and $8, B$. cinerea was recovered and fingerprinted successfully from throughout the plant, and all isolates were extremely similar. By contrast, isolates recovered from plant 4 were all distinct from one another, suggesting multiple independent infections.

\section{DISCUSSION}

B. cinerea was associated with $P$. xpolyantha seed in these experiments and surface sterilization was able to remove conidia from the seed coat with high efficiency. This suggests that the $B$. cinerea isolated from seed once they were surface sterilized was extremely likely to be from inside the seed. Visualization experiments will be needed to determine the position of this pathogen within the seed. In linseed, $B$. cinerea was associated with the outer integument (10) but primula seed are far smaller and $B$. cinerea mycelium might be less localized within the seed.

The proportion of $P$. xpolyantha seed infected was moderate, with a maximum of $22 \%$. This is higher than in faba bean, where 


\begin{tabular}{|c|c|c|c|c|c|c|c|c|c|c|}
\hline \multirow[b]{2}{*}{ Organ } & \multicolumn{10}{|c|}{ Plant number } \\
\hline & 1 & 2 & 3 & 4 & 5 & 6 & 7 & 8 & 9 & 10 \\
\hline Flowers & $1 \mathrm{a}$ & $\mathrm{u}$ & $\ldots$ & $\ldots$ & $8 \mathrm{~b}$ & $\ldots$ & 7 & $8 \mathrm{~b}$ & $\ldots$ & $\ldots$ \\
\hline Top leaf tip & $1 \mathrm{a}$ & $1 \mathrm{~b}$ & $1 \mathrm{e}$ & $\mathrm{u}$ & $\mathrm{u}$ & $6 a$ & 7 & $8 \mathrm{a}$ & 9 & $10 \mathrm{a}$ \\
\hline Top leaf base & $1 \mathrm{~b}$ & $1 \mathrm{~d}$ & $3 \mathrm{~b}$ & $7 \mathrm{a}$ & $\ldots$ & $\ldots$ & 7 & $\ldots$ & 9 & $10 \mathrm{~b}$ \\
\hline Bottom leaf tip & $1 \mathrm{a}$ & $3 \mathrm{a}$ & $3 \mathrm{~b}$ & $1 \mathrm{c}$ & $8 \mathrm{~b}$ & $6 a$ & $\ldots$ & $8 a$ & $\ldots$ & $10 \mathrm{a}$ \\
\hline Bottom leaf base & $1 \mathrm{a}$ & $3 a$ & $3 \mathrm{~b}$ & $\mathrm{u}$ & $\mathrm{u}$ & $6 \mathrm{~b}$ & $\mathrm{u}$ & $\ldots$ & 9 & $\mathrm{u}$ \\
\hline Roots & $1 \mathrm{c}$ & $1 \mathrm{e}$ & $\ldots$ & $8 \mathrm{~b}$ & $8 \mathrm{~b}$ & $8 \mathrm{c}$ & $\ldots$ & $8 \mathrm{c}$ & $10 \mathrm{~b}$ & $\ldots$ \\
\hline
\end{tabular}

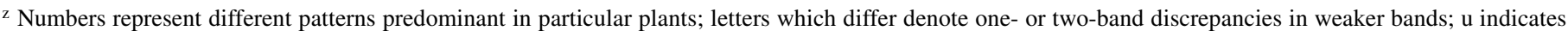
a unique pattern; and ... indicates inadequate or no amplification occurred from the extract or no isolation was made.

up to $8 \%$ of the seed have been found to be infected with $B$. fabae (11). At this percentage, seed transmission was considered to be important in initiating disease epidemics (11). In flax, much of the seed infection was superficial, with internal mycelium occurring only occasionally (15). Our studies suggest that distinct infection types may exist because some seed batches had no internal infection whereas, in others, a very large proportion was in-eradicable (Table 2, lines 4 and 5).

A large number of the primula seed were found to have Penicillium sp. and Rhizopus sp. associated with them, along with bacterial contaminants. In other host species, such as a Stylosanthes sp., pretreatment of the seed with $1 \%$ sodium hypochlorite has been found to increase the amount of $B$. cinerea isolated because there is a decrease in the development of Penicillium sp. and Rhizopus sp., which hinder the development of slowergrowing fungi (20). This may explain why we found a greater proportion of plants infected with $B$. cinerea in the plant propagator, where seed were sterilized, than expected from isolations from the unsterilized seed.

Using the isolation plant propagator, it was possible to demonstrate that $B$. cinerea was transmitted to growing $P$. xpolyantha plants from the seed, because no other source of infection was available. Sterilization of the soil did not decrease the amount of disease seen; therefore, soil could not be considered a major source of inoculum. B. cinerea has been shown to be transmitted to seedlings from infected seed; for example, in linseed (17), chickpea (6), and lentil (18). However, it has not previously been shown to be able to grow systemically within a plant without symptoms until the plant is fully mature.

$B$. cinerea was found throughout $P$. × polyantha plants as a latent infection at a high frequency in 4-week-old seedlings; frequencies of infection rose slightly in the next week and remained high until the plants had reached maturity. In the initial material, it was particularly noteworthy that, if a seedling was infected at all, all parts were infected. Neither observation is consistent with epidemiology involving only accumulation of individual conidial infections. Mature plant parts examined for latent $B$. cinerea showed a high level of disease in the roots, which is hard to explain other than by spread from elsewhere in the plant. Blakeman (3) found infection of lettuce roots by a specialized form of $B$. cinerea, which only attacked the remainder of the plant as it senesced. This differs from the present case in the localization of the infection. In this context, it is notable that isolates giving band pattern 8 appeared to be preferentially associated with roots in the plants from which isolates were taken for fingerprinting (Table 6). $B$. cinerea has been shown to grow systemically through the styles of various flower parts, such as black currant flowers (16), and within the vascular system of pear flowers (8), but it has not previously been shown to grow systemically through a growing herbaceous plant.

B. cinerea is well known to form latent infections within plants but this mainly is considered to be more in the form of a quiescent infection $(1,3)$, where the fungus germinates on the plant surface and remains dormant just under the epidermal cells. In our case,
$B$. cinerea was spread throughout $P$. xpolyantha plants and results using both genetic fingerprinting and the isolation propagator suggested that fully systemic infection by single isolates might be common. These results strongly suggest that $B$. cinerea frequently grows within $P$. $\times$ polyantha as a systemic infection. Infections via conidia from outside sources would explain the remaining sporadic infections in systemically infected plants. Further work is needed to determine whether systemic infection occurs in other species; our preliminary work suggests that $B$. cinerea often can be recovered from all parts of healthy commercial hybrid $\mathrm{Cy}$ clamen plants, also in the primulaceae.

Systemic $B$. cinerea infection of commercial $P$. xpolyantha may explain why the disease is sometimes hard to control with fungicides. This is observed in other species also: for example, even with very regular sprays of the fungicide captan, strawberry yield loses of 10 to $15 \%$ still occur due to $B$. cinerea infections (13). It is possible that partially or fully systemic infections contribute significantly to losses in this or analogous cases.

\section{ACKNOWLEDGMENTS}

This work forms part of a HortLink project (Hort 25) funded by the Department for Environment, Food and Rural Affairs (CSA 4189), Horticulture Development Council (PC/HNS 121), Campbell Scientific Ltd., and S. Coutts. The collaboration of ADAS Consulting Ltd., Horticulture Research International, Scottish Agricultural College, and Silsoe Research Institute is acknowledged.

\section{LITERATURE CITED}

1. Aadkaveg, J. E., Forster, H., and Thompson, D. F. 2000. Identification and Etiology of visible quiescent infections of Monilinia fructicola and Botrytis cinerea in sweet cherry fruit. Plant Dis. 84:328-332.

2. Barnes, S. E., and Shaw, M. W. 2002 Factors affecting symptom production by latent Botrytis cinerea in Primula $\times$ polyantha. Plant Pathol. 51:673-681.

3. Blakeman, J. P. 1980. Behaviour of conidia on aerial plant surfaces. Pages 115-151 in: The Biology of Botrytis. J. R. Coley-Smith, K. Verhoeff, and W. R. Jarvis, eds. Academic Press, London.

4. Braun, P. G., and Sutton, J. C. 1988. Infection cycles and populationdynamics of Botrytis cinerea in strawberry leaves. Can. J. Plant Pathol. 10:133-141.

5. Bristow, P. R., McNicol, R. J., and Williamson, B. 1986. Infection of strawberry flowers by Botrytis cinerea and its relevance to gray mold development. Ann. Appl. Biol. 109:545-554.

6. Burgess, D. R., Bretag, T., and Keane, P. J. 1997. Seed to seed transmission of Botrytis cinerea in chickpea and disinfection of seed with moist heat. Aust. J. Exp. Agric. 37:223-229.

7. Coertze, S., and Holz, G. 1999. Surface colonization, penetration, and lesion formation on grapes inoculated fresh or after cold storage with single airborne conidia of Botrytis cinerea. Plant Dis. 83:917-924.

8. De Kock, S. L., and Holz, G. 1992. Blossom-end rot of pears: Systemic infection of flowers and immature fruit by Botrytis cinerea. J. Phytopathol. 135:317-327.

9. Edwards, S. G., and Seddon, B. 2001. Selective media for the specific isolation and enumeration of Botrytis cinerea conidia. Lett. Appl. Microbiol. 32:63-66.

10. Harold, J. F. S., Fitt, B. D. L., and Landau, S. 1997. Temperature and effects of seed-borne Botrytis cinerea or Alternaria linicola on 
emergence of linseed (Linum usitatissimum) seedlings. J. Phytopathol. 145:89-97.

11. Harrison, J. G. 1978. Role of seed-borne infection in the epidemiology of Botrytis fabae on field beans. Trans. Br. Mycol. Soc. 70:35-40.

12. Jarvis, W. R. 1980. Epidemiology. Pages 219-250 in: The Biology of Botrytis. J. R. Coley-Smith, K. Verhoeff, and W. R. Jarvis, eds. Academic Press, London.

13. Legard, D. E., Martin, F. G., Xiao, C. L., and Chandler, C. K. 2000. Reduced sampling frequency for evaluating fungicide efficacy on Botrytis fruit rot of strawberry. Plant Dis. 84:743-748.

14. Malone, J. P., and Musket, A. E. 1964. Seed-borne fungi. Proc. Int. Seed Test Assoc. 29:177-212.

15. Maude, R. B. 1980. Disease control. Pages 275-308 in: The Biology of Botrytis. J. R. Coley-Smith, K. Verhoeff, and W. R. Jarvis, eds. Academic Press, London.

16. McNicol, R. J., and Willamson, B. 1989. Systemic infection of black currant flowers by Botrytis cinerea and its possible involvement in premature abscission of fruits. Ann. Appl. Biol. 114:243-253.

17. Mercer, P. C., and Ruddock, A. 1996. The effect of variety and fungicide on the yield and the incidence of pathogens on linseed in Northern Ireland. Plant Var. Seeds 9:101-110.

18. Morrall, R. A. A. 1997. Evolution of lentil diseases over 25 years in western Canada. Can. J. Plant Pathol. 19:197-207.

19. Mukherjee, G., and Mercer, P. C. 1994. Development of immunolabelling tools to study interactions between microorganisms in the biocontrol of seed-borne diseases of linseed. Brighton Crop Prot. Conf. Pests Dis. 937-938.

20. Nan, Z. B., and Hanson, J. 1998. Detection of seedborne fungi in Stylosanthes guianensis, S. hamata, and S. scabra. Seed Sci. Technol. 26:333345 .

21. Van der Plank, J. E. 1963. Plant Diseases: Epidemics and Control. Academic Press, New York. 